\title{
CONSUlting the SOUTH African EXPERTS IN Physiotherapeutic Stroke Rehabilitation
}

\begin{abstract}
This paper presents the opinions of expert physiotherapists on what constitutes optimal stroke rehabilitation in South Africa. Data were collected by the use of the Delphi technique. Consensus was reached after two rounds, and the respondents' views are summarised and discussed within the framework of South African health care. Results showed that physiotherapy was felt to be very important after stroke, and the survey created a profile of the skills that physiotherapists may require in order to work in this field.

HALE LA, MSc'; EALES CJ, Ph.D ${ }^{2}$

1 Lecturer, Deparment of Physiotherapy,

University of the Witwatersrand.

2 Professor of Physiotherapy, Department of Physiotherapy, University of the Witwatersrand and the Johannesburg Hospital. However, no new or innovative methods by which appropriate rehabilitation services could be delivered in South Africa were generated by the survey.

The Delphi technique is described and its use in this survey considered.
\end{abstract}

\section{KEYWORDS: STROKE, REHABILITATION, DELPHI TECHNIQUE}

\author{
This study was part of a dissertation submitted by Mrs. L.A. Hale to the University of the Witwatersrand for a Doctoral degree \\ in Physiotherapy, and was granted ethical clearance from the Committee for Research on Human Subjects, University of the Witwatersrand: \\ No. 950 111. The study was funded by the South African Medical Research Council and the University of the Witwatersrand.
}

$S^{s+n}$ troke is the second highest cause of death due to chronic diseases of lifestyle in South Africa (Fritz, 1997) resulting in between $8-10 \%$ of all reported deaths, and $7.5 \%$ of deaths in the country's workforce $(25$ - 64 years of age). The age-standardised mortality rate is $125-175 / 100,000$ (Neurological Association of South Africa Stroke Working Group, 2000). An increase in the incidence and mortality following cerebrovascular accident is predicted as life style risk factors, such as high cholesterol diets and smoking are added to the high prevalence of hypertension in South Africa's black population (Fritz, 1997; Seedat, 1998). More recently, the rampant epidemic of HIV/AIDS threatens to increase the incidence of stroke enormously (Hoffmann, 1998; Seedat, 1998). About $50 \%$ of all CVA survivors have some residual physical

\section{CORRESPONDENCE TO:}

Mrs L.A. Hale

School of Physiotherapy,

University of Otago,

P O Box 56, Dunedin,

New Zealand

Journal abstracts are online at:

http://www.ptglobal.net/ disability (Ashburn, 1999). Unfortunately, no data are available on the extent of residual disability amongst stroke survivors in South Africa but it is reasonable to conclude that it must be high. Given the above observations, there will probably be an increasing number of people with stroke requiring rehabilitation. The health care system in South Africa is already pressurised without this added burden (Wazakili and Mpofu, 2000). To put the problem into perspective, the Chris Hani (C.H.) Baragwanath Hospital, a 3240 bed hospital has 21 Physiotherapists and eight Physiotherapy Assistants. The hospital's "Neuro Team" attend to 90-100 new stroke patients every month (The C.H. Baragwanath Hospital Yearbook, 1998 - 1999). In 1998, the average length of hospitalisation following stroke at this hospital was found to be twelve days (Hale et al, 1998).

Following the Department of National Health's commitment to support Primary Health Care (PHC) in South Africa (1992), the University of the Witwatersrand revised its undergraduate physiotherapy curriculum in order that it met the requirements of PHC (Wallner and Stewart, 1994). Subsequent communication with both staff and students revealed that they often felt ill equipped to deal with community stroke rehabilitation. The appropriateness of the undergraduate neurorehabilitation course was thus questioned (Hale and Wallner, 1996). Historically the course had been based on models originating from more developed countries such as the United Kingdom and Australia, and the query arose as to whether this adequately prepared students to cope in their neurological clinical placements such as the C.H. Baragwanath Hospital or the Soweto clinics. As part of a research study emanating from this question, it was decided to survey the opinions of qualified South African physiotherapists regarded as experts by their colleagues in the field of stroke rehabilitation. What did these physiotherapists regard as optimal stroke rehabilitation in South Africa? This paper reports on the findings of this survey, which was conducted using a Delphi technique.

The Delphi technique is a method of gathering consensus information about a certain topic from a group of experts (Cohen and Manion, 1980; Shepard, 1993; Grbich, 1999). The Rand Corporation developed it during the 1950s. This corporation decided that face-to-face committee meetings had several limi- 
tations: there was intense social pressure to join the majority view; strong opinions tended to override weaker voices; people generally avoided conflict; there were clashes of personality; status problems meant that those further up the hierarchy were heard most often; and there tended to be undue emphasis on consensus or on changing opinions as an outcome. The corporation felt that in order to get more representation from its committee members, the interpersonal interaction would have to be eliminated. The Delphi method was thus developed.

The Delphi is characterised by four aspects: 1) anonymity of experts; 2) several rounds of questionnaires; 3) feedback between rounds; and 4) some form of statistically or descriptively analysed group response so that the strength of consensus can be seen (Seales and Barnard, 1998).

The Delphi technique can be used to collate and analyse the opinions of experts in a specialised field. This is usually achieved by sending sequential questionnaires to a selected group of people. Results of each round of questionnaires are fed back to respondents.

Jones et al (1999) successfully used this technique to survey specialist physiotherapists in the treatment of Parkinson Disease, in order to arrive at a framework of physiotherapy service delivery for this condition. They rated statements relating to physiotherapy management according to the context (where/how), the reasons (why), the actions (what) and the effects (how measured). Statements were then rated with adjectives such as happened/didn't happen, desirable/ undesirable and agreement/disagreement.

With the Jones et al (1999) study in mind, the present Delphi survey explored the following statements:

1. The importance of physiotherapy in stroke rehabilitation in South Africa.

2. How a physiotherapeutic service in stroke rehabilitation could be optimally delivered.

3. Where this service would be best delivered.

4. Which specific physiotherapeutic approach or philosophy is preferred for stroke rehabilitation

5. How the effects of this service delivery could best be measured.

\section{METHODS}

The first stage of the research involved the identification of possible participants by a peer review process. As the number of physiotherapists in South Africa with a special interest in stroke rehabilitation is limited, all known interested parties were included. The definition of "interested" were if the physiotherapist taught neurological physiotherapy at one of the eight universities; if they were post-graduate students in neurological physiotherapy; if they worked or had worked in neurology wards or neurological rehabilitation departments; or if they belonged to the Neurological Rehabilitation Group of the South African Society of Physiotherapy. In addition, physiotherapists were selected if it was known that they had an interest in neurological physiotherapy as applied in the community and if it was felt they could make a contribution to the process. Participants were asked if they knew of any other physiotherapists whom they felt could contribute. There is no consensus as to the optimal size of the "expert" panel (Williams and Webb, 1994), and the matter remains unresolved (Walker and Selfe, 1996). In this case, an attempt was made to obtain the greatest amount of "experts" in the field being investigated and from as many areas in the country as possible.

A questionnaire was mailed to the respondents by post and included an addressed, stamped return envelope. The following questions were asked in the first round of the survey:

1. Please state your opinion of the importance of physiotherapy in stroke rehabilitation.

2. In the context of South Africa, how do you feel stroke rehabilitation can best be delivered in order to achieve an optimal service?

3. There are many techniques (for example, Bobath, PNF, and Motor Relearning Programme) described for stroke rehabilitation. In your opinion, which of the techniques, if any, do you feel provides the best practice on which stroke rehabilitation in South Africa can be based.

4. How best can we measure the outcome of physiotherapy in stroke rehabilitation in South Africa?
The questions in the Round One questionnaire generated a number of statements in response. These statements were collated and used to develop a second questionnaire. This second questionnaire was then sent to the participants. The second questionnaire attempted to obtain consensus of opinion on the statements generated from Round One. Participants had an opportunity to see how other experts responded to the open-ended questions, to ensure that their own responses were included in an accurately identified category, and to suggest additional responses that appeared to be missing. The group was also invited to rank the responses to each question in the first questionnaire using a Likert-type scale. The categories: Strongly Agree, Agree, Neither Agree nor Disagree, Disagree, and Strongly Disagree were used. The Round Two questionnaires were analysed to obtain the percent of responses each statement on the questionnaire generated.

As consensus was achieved after Round Two, it was felt that a further round of questionnaires would not serve any specific purpose.

\section{RESIILTS}

Round One of the Delphi survey was sent to 41 physiotherapists. Twentyseven questionnaires were completed and returned (a response rate of $66 \%$ ).

Round Two Questionnaires were sent to all 41 participants. Those who had not responded in the first round were invited to join in the second round. A total of 32 questionnaires were completed and returned: a response rate of $78 \%$. As the actual responses were too many to publish, they have been summarised below:

\section{Please state your opinion of the importance of physiotherapy in stroke rehabilitation below.}

The statements generated by this question produced an extremely high level of consensus amongst participants. It was felt that physiotherapy was extremely important in all stages of stroke rehabilitation (acute through to chronic). The important roles that physiotherapists play include educating the 
patient, the family, the caregivers and the public; helping people with stroke to re-integrate back into the society (as one respondent stated: "in-patient rehabilitation helps patients with stroke adjust to their problems, and to start interacting with other members of the rehabilitation team and with people with similar problems"); helping patients achieve their maximal potential and become functionally independent; helping to improve their quality of life and assisting clients with stroke to learn to accept their ultimate handicap. Physiotherapists assist the caregivers of their clients, give clients good home programmes, and provide their clients with psychological and emotional support. It was felt that physiotherapy was important to improve the quality and normality of movement and function following stroke and in preventing the secondary complications of stroke. Physiotherapists form part of a team approach. All these statements drew agreement from more than $77 \%$.

Two respondents felt physiotherapists should expand their roles in the community: "there was still not enough follow through of rehabilitation into the community, and physiotherapists should be trained in health education," and "they need to expand their role to involve the whole community, not only caregivers or family." Two respondents felt that the South African Society of Physiotherapy should organise a "Stroke Week" in order to educate the public with regards to stroke.

The only statement that was controversial was whether physiotherapeutic stroke intervention is ideally performed in the patient's home. Twelve participants $(39 \%)$ said that they neither agreed nor disagreed, whereas 17 participants $(55 \%)$ agreed or strongly agreed. One respondent felt that "treatment in the home allows for very specific assessment and guidance of the patient in their own home environment." Only two participants disagreed, one of whom answered: "the role of physiotherapy is best in a hospital or clinic in the acute and sub-acute stages. Home care is not cost effective and it is doubtful whether our skills could be put to best use in the home environment. In the chronic stages following stroke, home exercises, maintenance and stroke exercises classes in an accessible community centre are required."

\section{In the context of South Africa, how do you feel stroke rehabilitation con best be delivered in order to achieve an optimal service?}

There was a $78 \%$ agreement that physiotherapy assistants and community rehabilitation workers (CRWs) can deliver a service to people with stroke, provided that physiotherapists act as consultants. To quote one respondent: "with the shortage of physiotherapists in South Africa, physiotherapy assistants and community rehabilitation workers should be used more effectively, but under the supervision of physiotherapists."

Education was perceived by most respondents as a crucial means of service delivery, and needed to be aimed at clients, caregivers, the general public, physiotherapy assistants and CRWs. Table 1 identifies some of the issues which respondents felt education programmes should address in a stroke rehabilitation programme.

Respondents suggested many methods by which stroke rehabilitation could best be delivered, and these are summarised in Table 2.

Again there were mixed feelings as to whether rehabilitation should be performed in the client's home or at an institution $(45 \%$ of respondents were undecided and $13 \%$ of respondents disagreed with home visits). One respondent stated: "Travelling is expensive and time-consuming and therefore not for South Africa. It would be better to access patients in community centres. There is basically a lack of money for rehabilitation following stroke." One respondent suggested "the use of mobile rehabilitation units or state funded rehabilitation centres".

Many respondents (64\%) felt that physiotherapists in the public health sector as well as those in the private sector should still provide one-on-one interventions. However, one respondent asserted that: "one-on-one rehabilitation is ideal but unrealistic. One would achieve more by empowering caregivers in the acute setting, such as the family or nurses" and that "physiotherapy needs to move out of institutions and the private sector and concentrate more on health promotion and prevention of stroke."

There was $100 \%$ concordance that early rehabilitation intervention after

TABLE 1. Issues to be included in an education programme.

\begin{tabular}{|l|c|}
\hline \multicolumn{1}{|c|}{ Issues to Address } & Respondent Agreement \\
\hline What is a stroke? & $100 \%$ \\
\hline The prevention of stroke. & $74 \%$ \\
\hline Physiotherapists' role in stroke rehabilitation. & $96 \%$ \\
\hline Prevention of caregiver burn-out. & $100 \%$ \\
\hline
\end{tabular}

TABLE 2. Methods of service provision

\begin{tabular}{|l|c|}
\hline \multicolumn{1}{|c|}{ Suggested Methods of Service Provision } & Respondent Agreement \\
\hline Dedicated stroke units & $100 \%$ \\
\hline Individual treatment & $64 \%$ \\
\hline Group therapy & $64 \%$ \\
\hline Home programmess & $97 \%$ \\
\hline Stroke support groups & $90 \%$ \\
\hline Community Rehabilitation Workers & $94 \%$ \\
\hline Primary Health Care Clinics & $97 \%$ \\
\hline Rehabilitation must be outcome-based and client-centred & $93 \%$ \\
\hline List of the resources available to stroke victims in all regions & $87 \%$ \\
\hline
\end{tabular}


TABLE 3. Consensus on techniques advocated as the best practice on which stroke rehabilitation in South Africa can be based.

\begin{tabular}{|c|c|c|c|}
\hline Approach to Rehabilitation & $\%$ Agreement & $\%$ Disagreement & $\%$ No Comment \\
\hline Bobath Approach & $49 \%$ & & \\
\hline Motor Relearning Programme & $24 \%$ & & \\
\hline Proprioceptive Neuromuscular Facilitation (PNF) & $19 \%$ & & \\
\hline Brunnström approach & $\begin{array}{c}35 \% \\
\text { (for upper limb } \\
\text { rehabilitation) }\end{array}$ & & $\begin{array}{l}23 \% \text { no comment } \\
29 \% \text { undecided }\end{array}$ \\
\hline Alfolter concept & $16 \%$ & & $\begin{array}{l}55 \% \text { had not heard } \\
\text { of this concept }\end{array}$ \\
\hline Bobath concept and PNF are impractical in SA context & & $65 \%$ & \\
\hline Manual Skills & & $67 \%$ & \\
\hline $\begin{array}{l}\text { Functional exercises, and that the quality of this functional } \\
\text { return was important }\end{array}$ & $80 \%$ & & \\
\hline $\begin{array}{l}\text { Applying Bobath principles to a client that is seen less than } \\
\text { once a week is futile. }\end{array}$ & $33 \%$ & $36 \%$ & \\
\hline The Bobath concept should be taught to caregivers and CRWs. & $65 \%$ & & \\
\hline $\begin{array}{l}\text { Motor Relearning Programme (MRP) could be taught at home } \\
\text { or in a group setting. }\end{array}$ & $62 \%$ & & \\
\hline $\begin{array}{l}\text { Motor Relearning Programme (MRP) could be utilised by CRWs } \\
\text { and caregivers under supervision. }\end{array}$ & $65 \%$ & & \\
\hline \multicolumn{4}{|l|}{ The MRP concept utilises a cognitive approach that is impractical } \\
\hline when there are language barriers. & $27 \%$ & $38 \%$ & \\
\hline None of the approaches mentioned were practical in SA. & $10 \%$ & $74 \%$ & \\
\hline
\end{tabular}

stroke is necessary and that one-on-one rehabilitation should be offered in the acute stage following stroke ( $84 \%$ agreement). An inter-disciplinary approach $(97 \%)$ should also be utilised.

Once the client has been discharged home, both individual and group therapy should continue $(71 \%)$. One respondent warned that: "group therapy is not ideal when patients are paying a lot of money to come for treatment" and thus it should be used effectively.

One respondent felt that continuing rehabilitation once discharged from hospital negates the principles of Primary Health Care and empowerment of the individual.

One statement proved to be quite controversial: "Rehabilitation should be functionally orientated, and the quality of function and movement may have to be sacrificed." There was only a $48 \%$ agreement with this statement. This response was-similar to that elicited from the assertion that the "western" approach to rehabilitation is often not appropriate and is often too complicated for the South African context (55\% agreement).

Seventy-one percent of respondents agreed with the statement that certain patients should be targeted for rehabilitation, the rationale being based on published studies of the prognostic indicators following stroke. One respondent felt that this could be construed as discriminatory practise.

There should be parliamentary lobbying to promote and improve rehabilitation policies $(93 \%)$, as well as targeting medical aid funders to supply better enumeration packages for neurological rehabilitation (96\%). Most respondents $(96 \%)$ felt that in private rehabilitation, better planning of the utilisation of the medical funds available for rehabilitation should ensure that funds were available for the later stages of rehabilitation as well.

3. There are many techniques (for exámple, Bobath, PNF, Motor Relearning Programme) described for stroke rehabilitation. In your opinion, which of the techniques, if any, do you feel provides the best practice on which stroke rehabilitation in South Africa can be based.

This question generated the most controversy amongst respondents as can be seen in Table 3. However, it was generally felt that a combination of approaches to rehabilitation was probably the best strategy to adopt.

There was some agreement (42\%) that approaches other than the Bobath/ NDT concept were difficult to comment upon as most training institutes in South Africa taught the Bobath/NDT concept and little was known of the other methods.

Seventy-five percent of the respondents concurred that management of clients should be based on a social model, and should be out-come based, have functional goals and set time frames with which to work (87\%).

One respondent felt that: "the best use must be made of the available environment, for example, in the home or in the institute, to facilitate increased activity which will serve to stimulate their 
patients to move and involve themselves with their environments", and another respondent concluded: "physiotherapists need to be innovative and creative to use their knowledge and skills to best advantage in any situation/context. The principles of various concepts should be taught, but the physiotherapist should move away from specific techniques and design intervention that suits the specific individual and the group or community they are serving."

\section{How best can we measure the outcome of physiotherapy in stroke rehabilitation in South Africa?}

Most of the respondents felt that improvement of a client's functional ability and of their quality of life were important parameters to measure $(94 \%$, $96 \%$ respectively). They felt that all stroke programmes should have indicators for monitoring and evaluation (94\%), and some of the indicators mentioned were independent function $(87 \%)$, return to work $(45 \%)$ and re-integration back into the client's community (65\%). Note must be taken of physical, emotional and social improvement (93\%). Clients must be regularly assessed, including both functional ability and at an impairment level $(71 \%)$. However, one respondent felt that "one must be careful as to whether one is measuring patientspecific outcomes or programme evaluation outcomes. Outcomes are also determined by the social problems of the area."

Specific scales of measurement were mentioned as being useful and these can be seen in Table 4.

Other tests mentioned by respondents included: the speed of walking (45\%); the speed, co-ordination and quality of movement $(65 \%)$; the use of specific questionnaires $(32 \%)$; the use of valid, reliable, effective, easy, quick international motor scales $(68 \%)$; and the development of a South African scale which reflects outcome within the client's specific environment (61\%). Assessing caregivers' opinions as to the success of intervention was suggested as one method of gauging outcome $(78 \%)$. The use of photographs and video recordings were other suggestions of measurement (52\%). Reaching realistic goals would be yet another appraisal that could be used $(90 \%)$.

One respondent commented that: "it is doubtful whether one scale would be useful in all South African situations and communities. It seems that each spectfic rehabilitation programme should use a scale to suit its goals and outcomes" and another respondent replied: "Do we need to measure it? If every physiotherapist could treat stroke patients well the outcomes will speak for themselves".

There was some concern that functional goals often clash with cultural beliefs $(36 \%)$ and a few respondents felt that outcome of stroke rehabilitation could not be measured (6\% agreed but $74 \%$ disagreed).

Suggestions for the future were the need for a disability census (55\%), and the need for more research, in particular randomised, controlled studies (74\%). A further suggestion was: "the department of Welfare have adapted a well researched disability instrument (the $D Q 98$ ) to measure in/dependence in elderly people in order to determine whether they require frail care. This takes into consideration a biopsychosocial approach and the stress on caregivers. This could be adapted to measure in/dependence in a wide variety of clients/patients." One respondent said that unfortunately: "outcomes scales are often difficult to implement due to the

TABLE 4. Suggested scales of measurement of stroke rehabilitation in South Africa

\begin{tabular}{|l|c|c|}
\hline \multicolumn{1}{|c|}{ Measurement Scale } & $\%$ Agreement & $\%$ No Opinion \\
\hline Canadian Neurological Scale (acute stage) & $6 \%$ & $61 \%$ \\
\hline Motor Assessment Scale (MAS) (subacute stage) & $23 \%$ & $29 \%$ \\
\hline Rivermead Scale (subacute stage) & $23 \%$ & $29 \%$ \\
\hline Functional Independent Measure (chronic stage) & $45 \%$ & $23 \%$ \\
\hline The Reintegration to Normal living (RNL) & $58 \%$ & $19 \%$ \\
\hline
\end{tabular}

lack of manpower and time." There was a warning that "over emphasis on measurement may be threatening for patients."

Two responses summarised this section: "it is important to use international scales, as it is important for research and for comparing results", however "scales need to be tailor-made to South Africa's cultural issues."

\section{DISCUSSION}

\section{Resulis of the Survey}

The results of the survey indicated that physiotherapists believe physiotherapy plays an important role in the rehabilitation of clients with stroke, in all three of the defined stages: acute, subacute and chronic. Pound and Ebrahim (1997) had similar findings regarding the positive outlook physiotherapists have on what they can offer people with stroke. Ideally most respondents in this study would like dedicated stroke rehabilitation units, although a good many felt rehabilitation should be performed in the client's home environment. However, the impracticalities of home visits were highlighted, such as time and financial constraints. It was acknowledged that getting the client to a medical facility was difficult due to problems with transport. A compromise would be the use of community centres, for example town halls and churches. Mobile rehabilitation clinics were suggested as one method of reaching out to clients. This may be a feasible idea. The Phelophepa Health train has been operating successfully since 1994, treating nearly 200,000 people around South Africa (Thom, 1998). A mobile rehabilitation bus could be used in more localised areas.

Most respondents advocated for the increased use of physiotherapy assistants or CRWs, but with physiotherapists acting as consultants, a view held by other physiotherapy service providers (Taukobong, 2000; Wazakili and Mpofu, 2000 ), and one which is probably worth exploring further.

Respondents felt that support groups should be encouraged. Group therapy itself was controversial with some believing it was very useful, and others 
feeling that it may be efficient (to see many clients at once) but not effective in achieving the desired results. However, structured group therapy can provide positive group dynamics such as psychological support, competition and motivation as well as creating selfreliance amongst group members in a participatory process (Ada, 1999; Stewart and Bhagwanjee, 1999).

Providing individual therapy to clients was still considered important by respondents both in private and government settings. This view however may not be possible given the shortage of physiotherapists and time constraints under which physiotherapists have to work, which probably prompted the comment from one respondent to "one-on-one rehabilitation is ideal but unrealistic. One would achieve more by empowering acute caregivers, such as the family or nurses". It would depend on what was defined as "individual" therapy, and the frequency and duration of this therapy. Unfortunately only people with a disability due to stroke who present to hospitals where adequate physiotherapy services are available, will in fact benefit from individual therapy. For many stroke victims, rehabilitation is either not available, or only available for a very short time. Follow-up once discharged is impossible in many cases. One respondent felt that: "Physiotherapists need to set 'ideal' goals but also need to reconcile these with the reality of health care in South Africa, and make services realistically available to the larger community, i.e. the best service for all, not the ideal service for a few".

The results of the survey created a picture of what is required in a physiotherapist involved in stroke rehabilitation. Attributes include an intimate knowledge of: stroke (what it is, its prevention and the prognostic indicators of outcome); the social model of rehabilitation in order to be client-centred and culturally sensitive; the latest in stroke research to ensure practice is outcome-based; skills to operate in a team; knowledge of adult education and teaching skills; and the ability to promote health and wellness. Creative thinking is required in order to make rehabilitation efforts appropriate when working in an institute or if giving stroke therapy in a group. None of these attributes are novel, they are often espoused, and training institutes are addressing these issues. However, it was noticeable in the last two statements of the survey, that many therapists had no notion of many of the latest techniques or of recent research. This may be due to a lack of exposure of therapists, unless they are in an academic situation, to the latest literature, and it might be something university departments or special interest groups could address. This lack of exposure is however not unique to South African physiotherapists. A recent survey of physiotherapists' reasons for selection of treatment techniques in the United Kingdom and Australia found that there was a virtual absence of the use of journal literature as a basis for selection. Instead there was an overwhelming reliance on formal education, such as initial undergraduate training and practice-related courses (Turner and Whitfield, 1999).

The important role physiotherapists have in health education was widely acknowledged, with one respondent going so far as to say: "physiotherapy needs to move out of institutions and the private sector and concentrate more on health promotion and prevention of stroke." Physiotherapists are often in a unique position to provide preventative education. However, as rehabilitationists, our educational role is far greater. While prevention is desirable, our defined role is the "restoration of optimal levels of physical, psychological and social ability ...." (Andrew, 1987) after the disabling event. We need to educate, to provide advice, which would enhance our clients' optimal return of functional ability, and thereby, their quality of life. It was interesting that one respondent felt that continuing rehabilitation once discharged from hospital negates the principles of Primary Health Care (PHC) and empowerment of the individual. The declaration at Alma Ata defined PHC as: "essential health care made universally accessible to individuals and families in the community by means acceptable to them, through their full participation and at a cost that the community and the country can afford" (WHO, 1979). This does not mean that rehabilitation should be discontinued after discharge. Rather it implies that rehabilitationists are required to provide a service in which there is equal partnership and ownership of the process both with the client and with their community. This means providing a rehabilitation service that the community defines as opposed to that which the health professional feels ought to be provided (Petrick et al, 1999). This would require a client-centred approach where the health professional listens carefully to what the client wishes and there is informed negotiation of what the professional can provide and the likely result of that intervention. The national government's White Paper on an Integrated National Disability Strategy (1997) is aimed at facilitating the empowerment of all people with disabilities and promoting their fullest development as equal citizens within society (Stewart and Bhagwanjee, 1999). This may require the physiotherapy profession to reconsider their role in the rehabilitation from one of the "restoration of optimal levels of physical, psychological and social ability ...." (Andrew, 1987) to one of enabling people with disability to have increased self-awareness and self-confidence within their level of ability (Brohier, 1998). In the book Empowerment of the Blind, Websons (1997, p.27) writes: "once we are empowered, we have personal power and control over our lives. We have positive self-images that are affirmed and sustained." A number of theoretical approaches and methodologies on empowerment have been developed by social scientists (Stewart and Bhagwanjee, 1999). These may help health professionals develop the necessary mind-shift from the historical medical model of rehabilitation to the national government's envisaged rehabilitation model set within a framework of human rights and development (Stewart and Bhagwanjee, 1999). Densen described this model of rehabilitation within a social context as "independent living" and defined it as" a concept, a policy, a set of communitybased services and programmes, and a 
civil-rights movement ... it is freedom to participate in the community fully and to have access to housing, transportation, health care, employment and education .... it is reflective of a self-determined and self-directed lifestyle that permits the individual to make meaningful choices" (Densen, 1988, p. 18).

The use of the NDT/Bobath approach appeared to be the technique or approach well favoured by many respondents for stroke rehabilitation in South Africa. However, the general feeling was that an eclectic approach based on the attainment of functional goals was the best strategy. The improvement in the quality of this functional movement was deemed important by many, however one respondent felt that "the quality of function and movement may have to be sacrificed." Although this proved to be a fairly controversial statement, it may be pragmatic given the lack of contact time in stroke rehabilitation. Published literature on the effects of rehabilitation after stroke have shown that there are weak associations between improved functional outcome and 1) the intensity of rehabilitation services, 2 ) the early onset of rehabilitation and 3) task-specific therapy services versus more generalised therapy (Cifu and Stewart, 1999; Kwakkel et al, 1999; Rice-Oxley, 1999). However, most intervention studies assess the presence or absence of certain functional skills rather than on the quality of co-ordination patterns of movement of theses skills (Kwakkel et al, 1999). There seems to be some evidence for the use of physiotherapy to improve functional ability following stroke, but a paucity of evidence on the positive effect of physiotherapy on the quality of movement.

Measuring the outcome of physiotherapy in stroke rehabilitation in South Africa did not generate much consensus or particularly strong points of view. It was generally felt that it was very important to monitor stroke rehabilitation programmes, and that the return of independent function and the improvement of the client's quality of life were the most important indicators. It must be emphasised, however, that any. programme instituted for stroke rehabilita- tion should be monitored and outcome measured to ensure the efficacy of such a programme. In order for stroke rehabilitation to exist, and for physiotherapists to be involved in it, physiotherapists have to justify their work. Justification will be demanded not only by the clients and the public but also by all involved funders, whether they are private or governmental (Turner and Whitfield, 1999). The use of valid and reliable outcome measures are a vital component of rehabilitation and should be taught in under-graduate training programmes to ensure the survival of the profession.

\section{The Use of a Delphi Survey}

The resultant report of a Delphi survey should indicate areas of consensus: spread of opinion, minority arguments and deviant responses. This was certainly attained in this survey, in spite of it only consisting of two rounds. Further questionnaires would not have added to the body of knowledge obtained or formed any further consensus of the more controversial issues.

Because the experts do not interact, the use of the Delphi prevents the potential problems that often occur in small, consensus-driven groups (Shepherd, 1993). The success depends on the diligence and motivation of the respondents in formulating considered opinions, and in their proficiency in communicating. The respondents of this survey showed a great deal of motivation with a good return rate to both rounds. Many of them went to a great deal of trouble communicating their thoughts.

The Delphi method has been criticised for its lack of "methodological rigour", for example, individuals may be influenced to conform because views are fed back to each member. The study may also fail to get a representative sample of experts. Different panels with similar expertise may produce different results (lack of reliability) and the validity of the results may be influenced by the response rates. In addition there is little agreement on the optimum number for the panels or on what constitutes "consensus" (Seales and Barnard, 1998). Jones and Hunter (1995) argue that the existence of a consensus does not mean that the "correct" answer has been found. The Delphi technique has an equal chance of producing collective ignorance as well as collective wisdom.

The validity and reliability of the Delphi method have not been well-evaluated (Walker and Selfe, 1996). One method of achieving a high concurrent validity is by achieving a consensus (Williams and Webb, 1994), however there is no standard threshold for consensus. Some authors have arbitrarily defined their own limits, for example, Boyce et al (1993) set consensus at 66\%, and McKenna (1994) suggested $51 \%$. In this survey, if the categories "agree" and "strongly agree" are combined into "agreed", and those of "disagree" and "strongly disagree" into "disagreed", then there was a consensus of over $70 \%$ in 62 out of the 100 statements made by the participants. Statements reaching between 50\% - 70\% consensus numbered 21 . Of those that were under $50 \%$ consensus, six statements had a "no opinion" response greater than $56 \%$. The majority of the controversial statements were generated by the third and fourth questions where participants had to comment on which treatment technique and measuring tool they felt were appropriate for stroke rehabilitation in South Africa. Many had no opinion with regards to statements in these areas. Thus it was felt that although consensus in these areas was not as high as the other sections, continued rounds of questioning would not produce any further useful information. Most studies limit the number of rounds to two or three to prevent respondent fatigue and increased attrition (Whitman, 1990).

In spite of this method of uninfluenced, equal and anonymous participation, there has been debate regarding its ability to reduce psychosocial variables (O'Brien, 1978). Johnston (1970) was concerned on the capabilities of the "experts" to develop future, alternative solutions to problems whose current practice they well may have influenced.

The Delphi method has been criticised for its methodology that does not allow participants a chance to discuss their responses (Jones and Hunter, 1995). Many of the respondents in this survey felt that they would have liked to clarify their rating of statements. 
Thus the results of this survey may not produce the "correct" answers to the problems facing stroke rehabilitation in South Africa. They can only be used to generate ideas and to gauge opinions. Readers must guard against placing too much reliance on quantitative conclusions from the results of Delphi surveys (Jones and Hunter, 1995). These surveys are generally used to produce consensus statements that must then be tested with more rigorous methodological methods. In-depth interviews may have been a better alternative to the Delphi in this study. A deeper understanding of the "experts" thoughts would have been attained, allowing them the chance to clarify and explain their ideas more accurately. However, due to financial constraints, this would have limited the number of "experts" interviewed.

\section{Response Rate}

The response rate of Round One $(66 \%)$ was deemed adequate, given that a couple of the selected physiotherapists were out the country at the time, and that a few of the envelopes were returned with the address of the recipient unknown. In addition, the survey was conducted at a time when the South African postal services were still considered inefficient. Unfortunately, not all of the identified "experts" had e-mail addresses. A response rate of $70 \%$ or more is considered acceptable for a postal questionnaire in a Delphi survey (Bork, 1993). The second round questionnaire generated a higher response rate of $78 \%$. This survey invited non-respondents from the first round to contribute to the second round if they so wished. This is an acceptable practice (Walker and Selfe, 1996).

\section{CONCLUSION}

This article presents the results of a Delphi survey of physiotherapists who have experience or an interest in neurorehabilitation. It summarises their opinions of what constitutes optimal stroke rehabilitation in South Africa. A Delphi technique was used in an attempt to obtain the participating physiotherapists' independent views, without these opinions being influenced by the collective thought of a committee. This paper does not offer a solution of what should be taught regarding stroke rehabilitation at an undergraduate level, but is rather a synopsis of what qualified physiotherapists currently view as optimal practise, and in this role, the survey has generated some ideas which could be debated further.

Are these ideas realistic? Is what is viewed as an optimal approach able to provide rehabilitation to all people with stroke who require it within the socio-economic constraints prevailing presently in South Africa? Or do we require more innovative ideas, perhaps a fresh approach to stroke rehabilitation in South Africa? The only way these questions can be answered is if data regarding the incidence of disability following stroke and the outcome of intervention, are closely monitored and reported.

\section{REFERENCES}

Ada L, Mackay F, Heard R 1999 Stroke rehabilitation: does the therapy area provide a physical challenge? Australian Journal of Physiotherapy 45: $33-39$

Andrews K 1987 Rehabilitation of the Older Adult. Ist edition, London: Edward Arnold

Ashburn A 1999 Physical recovery following stroke. Physiotherapy 83(9): $480-490$

Bork C E 1993 Research in Physical Therapy. Ist edition, Philadelphia, J B Lippincott Company.

Boyce W, Gowland C, Russell D 1993 Consensus methodology in the development and content validation of a gross performance measure. Physiotherapy Canada 45(2): 94 - 100.

Brohier W G 1998 Empowerment or impoverishment. Action Aid Disability News 9(2): $56-58$.

Chris Hani Baragwanath Hospital Yearbook 1998 - 1999 Johannesburg: Transworld Group.

Cifu D X, Stewart D G 1999 Factors affecting functional outcome after stroke: a critical review of rehabilitation interventions. Archives of Physical Medicine and Rehabilitation 80: s-35-S-39.

Cohen L, Manion L 1980 Research Methods in Education. London: Croom Helm.
Densen C R 1988 Independent living: public policy issues. American Rehabilitation 1: $12-16$.

Fritz V U 1997 Stroke incidence in South Africa. South African Medical Journal 87(5): $584-585$.

Grbich, C. 1999. Qualitative Research in Health; an introduction. Ist ed., Australia: Allen and Unwin, pp $116-120$.

Hale L A, Eales C J 1998 Recovery of walking function in stroke patients after minimal rehabilitation. Physiotherapy Research International 3(3): $194-205$

Hale L A, Wallner P J 1996 The challenge of service provision in South Africa for patients with hemiplegia. Physiotherapy 82(3): $156-158$

Hoffmann M W 1998 The Durban stroke data bank with special emphasis on higher cortical function deficits [thesis]. Durban: Department of Neurology, University of Natal.

Johnston D 1970 Forecasting methods in the social sciences. Technological Forecasting and Social Change: $173-187$

Jones D, Plant P, Lovegreen B 1999 A framework for physiotherapy service delivery in Parkinson disease [abstract]. Proceedings of the 13th International Congress of the World Confederation for Physical Therapy: 128

Jones J, Hunter D 1995 Consensus methods for medical and health services research. British Medical Journal 31 I: $376-380$

Kwakkel G, Wagenaar R C, Koelman T W 1997 Effects of intensity of rehabilitation after stroke: a research synthesis. Stroke 28: 1550 $-1556$

McKenna H P, 1994 The Delphi technique: a worthwhile research approach for nursing? Journal of Advanced Nursing 19: 1221 - 1225

Ministry in the Office of the President 1997 White Paper on an Integrated National Disability Strategy. Gauteng, South Africa

Neurological Association of South Africa. 2000 Stroke therapy clinical guideline. South African Medical Association - Neurological Association of South Africa Stroke Working Group. South African Medical Journal 90 (3 Pt 2): $276-278,280-298$.

O'Brien P 1978 The Delphi technique: a review of the research. South Australia Journal of Education Research 1(1): 57 - 75 
Petrick M, Homer S, Evans R 1999 Are therapists aware of the needs of people with disabilities? South African Journal of Physiotherapy 55(1): $26-28$

Pound P, Ebrahim S 1997 Redefining 'doing something': Health Professionals' views on their role in the care of stroke patients. Physiotherapy Research International 2(2): $12-28$.

Rice-Oxley M 1999 Effectiveness of brain injury rehabilitation. Clinical Rehabilitation 13(suppl 1): $7-24$

Seales J, Barnard S 1998 Therapy Research: Processes and practicalities. Oxford: Butterworth-Heinemann, 1st edition: 36 - 40

Seedat Y K 1998 The prevalence of hypertension and the status of cardiovascular health in South Africa. Ethn Dis 8(3): 394 - 397

Shepard K F 1993 Questionnaire design and use. In: Research in Physical Therapy. Bork C E (editor). 1st edition, Philadelphia: J.B. Lippincott Company: 176 - 204

Stewart R, Bhagwanjee A 1999 Promoting group empowerment and self-reliance through participatory research: a case study of people with physical disability. Disability and Rehabilitation 21(7): 338 - 345

Taukobong N P 1999 The role of the community based rehabilitation worker within the primary health care service of the Odi District. South African Journal of Physiotherapy 55 (1): $19-22$

The Department of National Health and Population Development. 1992: A new health dispensation for South Africa.

Thom A 1998 Health Train: a rural winner. The Star Newspaper, Johannesburg, July 21: 13

Turner P, Whitfield T W A 1999 Physiotherapists' reasons for selection of treatment techniques: a cross-national survey. Physiotherapy Theory and Practice 15: 235 - 246

Walker A M, Selfe J 1996 The Delphi method: a useful tool for the allied health researcher. British Journal of Therapy and Rehabilitation 3(12): $677-681$

Wallner P J, Stewart A 1994 A community approach to physiotherapy. South African Journal of Physiotherapy 50(3): $54-56$
Wazakili M, Mpofu R M B 2000 Physiotherapy service providers' views on issues of assistants: are physiotherapy assistants required? South African Journal of Physiotherapy 56(4): $22-25$

Webson W A 1997 Empowerment of the Blind. A Handbook for Organisations of and for the Blind and Visually Impaired. Watertown: World Blind Union Institutional Development Project, The Hilton/Perkins Program.

Whitman N 1990 The committee meeting alternative: using the Delphi technique. Canadian Journal of Nursing Administration $20(6 / 7): 30-36$

Williams P L, Webb C. 1994 The Delphi technique: a methodological discussion. Journal of Advanced Nursing 19: $80-186$

World Health Organisation 1979 Health for All. Series No. 2. Strategies for health for all by the year 200 . Geneva: WHO.

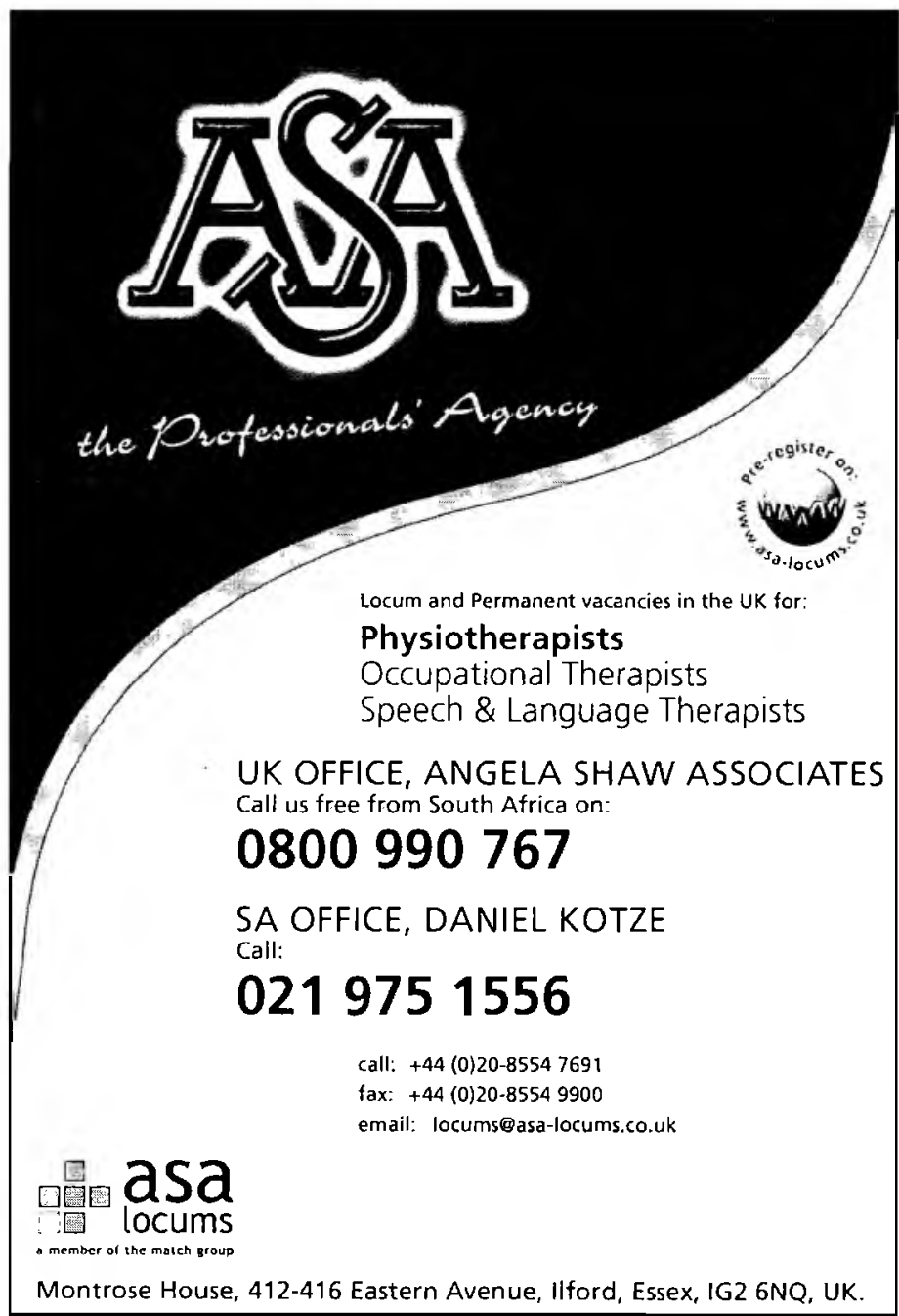

\section{GOVERNMENT OF THE SULTANATE OF OMAN MINISTRY OF HEALTH}

Tax-free salary + accommodation +48 days' poid holiday + excellent benefits

\section{PHYSIOTHERAPY SLIPERVISOR}

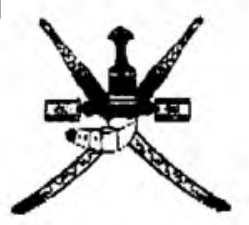

Applications are invited for the above posts by the Ministry of Health in the Sultanate of 0 man.

Oman is a pragressive country with breathtaking scenery and many opportunities for outdoor activities as swimming, scubo diving, photography etc.

\section{Requirements:}

- Degree ar Diploma in Physiatherapy followed by at least 6 years' post degree/diploma experience with at least two years at a senior level with a relevant validated postgraduate course.

The successful candidate will undertake the supervision and educatian of junior staff and be an active participant in an angoing inservice education programme.

\section{Solory \& Scale:}

R.0.787/-per month with onnual increments of R.0.20/- per month to maximum of scale, which is R.0.981/- per month. One Riyal Omani is equivalent to 2.57 U.S. Dollars approximately.

Benefits include free, furnished (hard furnishings only) air-conditianed accommodation. Ecanamy class oir fickets ore provided to employee an initial appointment ond on final exit. $75 \%$ of the cost of an Economy Class air ticket is paid for onnual leave travel once during the coniractual year. Paid annual leave is $\mathbf{4 B}$ days. Allowances will be given for transport, water and electricity when these are nol provided free by the Ministry. Medical treatment within the Sultanale is free. The contracts are for ane year and ore renewable annually if agreeable to both parties.

Please apply with the names of 3 referees, a full curriculum vilae, copies af professional and experience certificates and a recent passport-sized phalagraph ta:

\section{Director of Personnel Affairs} Ministry of Health

Post Box 393, Muscat, Postal Code 113 Sultanate of Oman. 